\title{
Asian elephants (Elephas maximus) reassure others in distress
}

Contact directed by uninvolved bystanders toward others in distress, often termed consolation, is uncommon in the animal kingdom, thus far only demonstrated in the great apes, canines, and corvids. Whereas the typical agonistic context of such contact is relatively rare within natural elephant families, other causes of distress may trigger similar, otherregarding responses. In a study carried out at an elephant camp in Thailand, we found that elephants affiliated significantly more with other individuals through directed, physical contact and vocal communication following a distress event than in control periods. In addition, bystanders affiliated with each other, and matched the behavior and emotional state of the first distressed individual, suggesting emotional contagion. The initial distress responses were overwhelmingly directed toward ambiguous stimuli, thus making it difficult to determine if bystanders reacted to the distressed individual or showed a delayed response to the same stimulus. Nonetheless, the directionality of the contacts and their nature strongly suggest attention toward the emotional states of conspecifics. The elephants' behavior is therefore best classified with similar consolation responses by apes, possibly based on convergent evolution of empathic capacities. 


\title{
Asian elephants (Elephas maximus) reassure others in distress
}

\author{
Joshua M. Plotnik ${ }^{1 *}$ and Frans B. M. de Waal ${ }^{1}$
}

4

1. Living Links, Yerkes National Primate Research Center, and Department of Psychology, 36 Eagle Row, Emory University, Atlanta, GA, USA

Contact: Joshua M. Plotnik, Joshua.Plotnik@gmail.com

7

*Current Address: Mahidol University - Kanchanaburi, Division of Biological and Natural Resource Sciences, Sai Yok, Kanchanaburi, 71150 Thailand

9 KEYWORDS: consolation, elephants, conflict resolution, targeted helping, convergent cognitive 10 evolution 


\section{Introduction}

12 Most empirical evidence for how animals react to others in distress comes from the study

13 of conflict resolution (de Waal \& van Roosmalen, 1979; de Waal \& Aureli, 1996; de Waal, 2000).

14 Peacekeeping mechanisms have evolved to manage conflict in animal societies (see de Waal,

15 1996; de Waal, 2000 for a review), including reconciliation (i.e. affiliative physical contact

16 between former opponents soon after a conflict) and consolation (i.e. affiliative physical contact

17 from an uninvolved bystander directed toward a recipient of aggression). The former is much

18 more common than the latter in the animal kingdom, possibly due to differences in the

19 complexity of underlying cognitive mechanisms (de Waal \& Aureli, 1996; de Waal, 2008).

20 Although reconciliation appears to be self-interested for all individuals involved due to the need

21 to maintain valuable relationships, the significance of consolation for the bystander is still unclear

22 (de Waal, 2000). Recent work trying to identify the adaptive function(s) of consolation has

23 focused on a) the identity of bystanders and their relationships with the consolation recipient

24 (Romero, Castellanos \& de Waal, 2010; Romero \& de Waal, 2010; Romero, Castellanos \& de

25 Waal, 2011), b) the physiological changes in distressed individuals consoled by bystanders

26 (Koski \& Sterck, 2007; Fraser, Stahl \& Aureli, 2008), and c) possible benefits to the consolers

27 themselves (Koski \& Sterck, 2007; Koski \& Sterck, 2009). All of these possible functions

28 suggest that the parties involved initiate or accept contact as a way of mitigating emotional stress

29 responses (de Waal, 2008; Koole, 2009).

30 Because of these functional uncertainties, some scientists remain reluctant to use

31 functional or motivational terminology, such as consolation; instead, the aforementioned behavior

32 is sometimes described as "third-party affiliation" (a descriptive term that specifies only directed,

33 physical contact with a distressed individual, e.g., Call, Aureli \& de Waal, 2002; Koski \& Sterck,

34 2007; Seed, Clayton \& Emery, 2007). However, other studies argue that the mammalian capacity

35 for empathy underlies consolation (Preston \& de Waal, 2002), and compare the morphology and 
motivation of the behavior with "sympathetic concern" in humans (Romero, Castellanos \& de

Waal, 2010; Clay \& de Waal, 2013). In general, demonstrations of consolation in animals are rare, with empirical evidence thus far provided only for the great apes, canines, and certain corvids (de Waal \& van Roosmalen, 1979; de Waal \& Aureli, 1996; Palagi, Paoli \& Tarli, 2004;

40 Cordoni, Palagi, Borgognini Tarli, 2006; Mallavarapu et al., 2006; Seed, Clayton \& Emery, 2007;

41 Cools, van Hout \& Nelissen, 2008; Palagi \& Cordoni, 2009; Fraser \& Bugnyar, 2010; Romero,

42 Castellanos \& de Waal, 2010; Romero \& de Waal, 2010), but not for monkeys or any other species (e.g. de Waal \& Aureli, 1996; Schino et al., 2004; Watts, Colmenares \& Arnold, 2000, but see Call, Aureli \& de Waal, 2002; Wittig et al., 2007 for examples of comparable affiliative behavior). This rarity may be due to the potential cognitive underpinnings of consolation, such as empathic perspective-taking (de Waal, 2008), or else to species-specific social dynamics that determine how animals mitigate social strife in a variety of relationships. In some monkey societies, for example, it may be too risky to associate with victims of aggression due to the strictness of their linear hierarchies (de Waal \& Aureli, 1996; de Waal, 2000). close bonding with family members (Douglas-Hamilton \& Douglas-Hamilton, 1975; Moss, 1988;

52 Poole, 1996; Schulte, 2000; Payne, 2003; Bates et al., 2008). They often act as allomothers toward others' offspring, and respond immediately to the vocalizations of these individuals (e.g.

54 in response to infant distress - Lee, 1987; Bates et al., 2008). They are also known for their "targeted helping," or directed assistance that takes the specific needs of others into account (e.g. helping to lift and coordinated bracing of injured, dying or otherwise prostrate family members -

57 Douglas-Hamilton et al., 2006; Bates et al., 2008). Targeted helping is viewed as a sign of

58 empathic perspective-taking (e.g., Preston \& de Waal, 2002; de Waal, 2008).

In the present study, we aim to assess the affiliative tendencies of Asian elephants 
used in the conflict resolution literature. To our knowledge, this is the first systematic

62 investigation of distress-related affiliation in elephants based on a priori hypotheses (but see

63 Bates et al., 2008 and Hart, Hart \& Pinter-Wollman, 2008 for other possible displays of empathy

64 and stress-related emotional responses).

65 Relative to chimpanzees (de Waal, 1982; de Waal \& Aureli, 1996), elephants do not often

66 engage in conflict within their herd, which consists primarily of related females and immature

67 offspring (Douglas-Hamilton \& Douglas-Hamilton, 1975; Moss, 1988; Poole, 1996; Payne, 2003;

68 de Silva, Ranjeewa \& Kryazhumskiy, 2011). Thus, we measured how elephants affiliate or

69 reassure others as a response to an individual's distress irrespective of its cause. We recognize

70 that our inability to identify a clear stimulus for each distress event makes it difficult to

71 differentiate between cases where individuals are reacting directly to the stimulus or to another

72 elephant's distress. Because of this, it is unclear if all or most cases of affiliative contact can be

73 classified as "consolation" in the way this label is used in other post-conflict studies (e.g., Call,

74 Aureli \& de Waal, 2002; Preston \& de Waal, 2002; Koski \& Sterck, 2007; Seed, Clayton \&

75 Emery, 2007; Cools, van Hout \& Nelissen, 2008; Fraser, Stahl \& Aureli, 2008; Koole, 2009;

76 Koski \& Sterck, 2009; Fraser \& Bugnyar, 2010; Romero, Castellanos \& de Waal, 2011). Instead,

77 we refer to the elephants" affiliation with others as "reassurance" to note our focus on both

78 affiliative contacts and emotional responses. We use this term instead of "consolation" to avoid

79 implying the potential function of the elephants' behavior.

80 This study tries to distinguish the affiliative tendencies of elephants in response to

81 behaviorally identified stress. Based on the aforementioned social complexity of and targeted

82 helping in elephants, we predicted that reassurance behavior toward distressed individuals should

83 be identifiable through an assessment of physical and vocal contacts. If elephants are responsive

84 to the distress of others, they should be expected to make physical or vocal contact with stressed

85 conspecifics, and do so sooner than in control periods during which the conspecifics do not 
86 display distress. In addition, we might expect emotional contagion - bystanders' adoption of the

87 emotional state of those in distress - to be part of such a reaction if the elephants' affiliative

88 behavior is part of a more complex, emotionally driven social response (Zahn-Waxler,

89 Hollenbeck \& Radke-Yarrow, 1984; Zahn-Waxler \& Radke-Yarrow, 1990; Zahn-Waxler et al.,

90 1992; de Waal, 2003; de Waal, 2008; Clay \& de Waal, 2013). Thus, we predicted that the

91 elephants' behavioral and emotional responses would mimic physically and follow temporally

92 those of distressed conspecifics. Matriarchal elephant herds exhibit close social bonding and

93 often display varying levels of emotional reactivity (e.g., Moss, 1988; Poole, 1996; Schulte,

94 2000; Payne, 2003; Bates et al., 2008). Because of this, we also considered that emotional

95 contagion, found in many mammals (see de Waal, 2003; de Waal, 2008), might lead to affiliative

96 interactions among bystanders as well. Thus, we also predicted that bystanders to distress would

97 make physical or vocal contact with one another, in addition to, or instead of contact with the first

98 stressed individual.

99 Materials and methods

100 Ethics statement

101 This project was approved by the National Research Council of Thailand and Emory University's

102 Institutional Animal Care and Use Committee (ID 219-2007Y).

103 (a) Study area and subjects

104 This study was conducted at the Elephant Nature Park (the "Park") in the Mae Tang district of

105 Chiang Mai province, Thailand. Although the Park owns many of the elephants on-site, some are

106 leased or contracted so that the general elephant population changed regularly during the study

107 period. The data in this study refer to 26 elephants with approximate ages ranging from 3-60

108 years old, although due to unverifiable records, ageing elephants precisely was impossible.

109 Although genetic tests on the relatedness of the elephants were never done, it is reasonable to

110 conclude based on the relayed life histories of the individual elephants that all individuals, except 
111 for mother-juvenile pairs brought to the Park together, were unrelated. Each elephant was taken

112 care of by one or two mahouts (elephant caretakers) every day. Adult male elephants $(\mathrm{n}=4)$ were

113 completely excluded from the study as they were regularly prevented, for safety and husbandry

114 reasons, from participating in most of the natural, social interactions within groups. When a

115 female was first brought to the Park, she was generally allowed to integrate with a smaller group

116 of elephants. In this study, these smaller, social units (generally of $n=5-7$ individuals) are

117 labeled "managed groups" because they consisted of individuals that spent most of their social

118 time together under the guidance of their mahouts. There was no single herd at the Park, but six

119 individual managed groups that interacted at specific times during the day. These groups were

120 delineated based on interviews with the Park mahouts during data collection but prior to data

121 analysis.

122 Each day, elephants followed a specific routine established by Park management.

123 Mahouts moved their elephants to a specific location on the property, as a managed group,

124 beginning at 0700 hours. They ate at a central location at 1130 hours - fed either by their mahouts

125 or visiting tourists - bathed communally at 1300 hours and 1630 hours, and returned to their

126 night shelters, in which they were tethered for the night, at 1700 hours. Mahouts moved elephants

127 with vocal commands or by grasping their ears or legs and walking them to different locations on

128 the property. Throughout the day, elephants were left to graze or play in various parts of the

129 property within their social groups. Although individual elephants were generally allowed to

130 interact with members of other managed groups, the mahouts often intervened at unpredictable

131 times to separate volatile pairings.

132 (b) Defining Distress

133 Because there is very little literature on Asian elephant behavior in general (but see Sukumar,

134 2003; Sukumar, 2006; de Silva, Ranjeewa \& Kryazhimskiy, 2011), the more detailed literature on

135 African elephant behavior (Loxodonta genus - e.g., Douglas-Hamilton \& Douglas-Hamilton, 
136 1975; Moss, 1988; Poole, 1996; Payne, 2003) is often applied to Asian elephants as well because

137 of their relatively close phylogenetic proximity (Payne, 2003). Douglas-Hamilton and Douglas-

138 Hamilton (1975) and Lee (1987) describe distress in individual elephants, specifically infants,

139 based on specific vocalizations and stimuli. Infants give a specific call - either an infant roar or

140 squeal - and assume an alert posture where the head is raised, the ears are extended, the tail is

141 raised and the trunk is either raised or stiffened outward (Olson, 2004). Roars, rumbles, and

142 trumpets are often given in response to infant distress calls, or as a signal of an adult's own

143 distress. Using 1) Lee (1987)'s definition of distress events in calves as those that result in "a

144 dramatic response on the part of other animals ... rushing to assist the calf” (p. 287), 2) Bates et

145 al. (2008)'s definition of empathic responses to distress as: “A voluntary, active response to

146 another individual's current or imminent distress or danger, that actually or potentially reduces

147 that distress or danger" (p. 208), and 3) a comprehensive ethogram of elephant behavior with

148 specific attention to those behaviors occurring when an infant or adult is distressed or agitated

149 (adapted and expanded from Olson, 2004), we define a distress event in elephants as follows:

$150 \quad$ A distress event is one resulting from an unseen or seen negative stimulus (e.g. mahout-

151 driven separation or movement of individuals, conspecific intimidation or aggression, group

152 separation, environmental threat or accident) that causes an individual to become agitated and

153 to signal such agitation to others (which can be visually identified with specific changes in body

154 state - ears forward, tail erect - and movement, and acoustically identified by various

155 vocalizations, specifically trumpets, roars and rumbles).

156 (c) General Data Collection

157 We chose locations on the property from which to collect data to ensure both a full view of pre-

158 selected managed groups and the observer's safety. These locations included viewing platforms

159 constructed specifically for observations, and in fields in close proximity to mahouts.

160 Observation locations were chosen based on three factors in decreasing priority: 1) safety of

161 observation vantage point at any given time, 2) view of a maximum number of managed groups

162 at the beginning of the observation period, and 3) view of the managed groups from which there 
163 were the least amount of data. The property was approximately 55 acres in total size, but only 30

164 acres were observable for this study. The property was divided into four grids for observation

165 purposes, and an observation location was chosen within a grid based on the aforementioned

166 factors.

167 On average, data were collected during 1-2 week periods each month from April, 2008 -

168 February, 2009. General observation periods ran for no less than 30 minutes and no more than

169180 minutes per session from 0730 - 1030 and from 1400 - 1630, with scan samples taken every

17010 minutes. Data on proximity distance only were collected for relationship quality within

171 elephant groups. All observation periods began after 10 minutes of no mahout interference on

172 elephant behavior, and individual scan samples were cancelled if such interference occurred

173 within a given 10-minute period. All-occurrence sampling was used for distress behaviors and the

174 reactions of others to these behaviors (Altmann, 1974). In addition, if an interaction was clearly

175 and completely observed outside these specific observation periods, the same data were collected

176 ad-libitum ( $<20 \%$ of total cases), and a subsequent control observation period (see below) was

177 scheduled.

178 (d) Post-distress data collection - PD and MC observations

179 Although the human staff responsible for the elephants' care artificially constructed the 180 managed group over several years, we focused on spontaneous, affiliative behavior reflective of

181 natural, social interactions (de Waal, 1982; Sukumar, 2003; Sukumar, 2006; de Silva, Ranjeewa, 182 Kryazhimskiy, 2011). Post-distress data for this study were collected at the Park on 26 semi-free 183 ranging individuals in six managed groups following the PC (post-conflict, or PD, post-distress) /

184 MC (matched-control) methodology developed for reconciliation and consolation behavior in 185 primates (de Waal \& Yoshihara, 1983; see Materials and methods for details).

186 The PD period was an observation period in which all approach and affiliative behavior 187 was recorded (as were all data on potential stimuli for distress, individuals present within $50 \mathrm{~m}$, 
188 and date, time and weather), for a 10-min block following the first distress display. We chose a

189 10-min duration because it a) follows the methodology employed with many other non-human

190 species (see Aureli and de Waal, 2000 for a review), and b) far exceeded the average time of first

191 bystander response to another's distress in a baseline observation period conducted by the first

192 author prior to the start of data collection. Because elephant interactions may involve multiple

193 distressed individuals (Lee, 1987), the first individual to vocalize, or display a distress behavior

194 was labeled the victim and thus the focal individual in each PD period. If more than one

195 individual responded simultaneously, the rarest case (if known, the least-often distressed

196 individual) was chosen for observation. Each PD period was compared to an MC (matched

197 control) period, or another 10-min block of observation taken of the victim and bystanders on the

198 next possible day following the PD. An MC period was selected when as many variables from the

199 PD - in prioritized order: high percentage of original individuals present, location, time of day

200 and weather - could be maintained, and, most importantly, no new distress event occurred in the

20130 minutes prior to (or during) the period of observation. An MC was collected within seven days

202 of its corresponding PD (in $80 \%$ of PD/MC cases, the MC was collected within 48 hours). If an

203 MC was conducted when an elephant that had made contact with the distressed individual in the

204 corresponding PD was absent or more than $25 \mathrm{~m}$ away, that PD/MC observation was excluded

205 from the analysis to avoid biasing the data in favor of our predictions.

206 (e) Scan-Sampling for Proximity - "Friends" and "Non-Friends"

207 We attempted to differentiate between contact directed toward "friends" (closely-bonded

208 individuals) and "non-friends" (those outside managed groups) by collecting 68 hours of scan-

209 sampling proximity data (for procedure, see Romero \& de Waal, 2010). Although mahouts did

210 not interfere with most day-to-day social interactions within established, managed groups (and

211 thus we were able to specify controlled parameters for the PD/MC data), they often

212 discriminately prevented outsider elephants from coming too close to avoid potential conflict. 
213 Such conflict between elephants at the Park was also not representative of natural, wild elephant

214 groups (in which conflict is relatively rare), probably due to a high level of unrelatedness within

215 and between managed groups at the Park. Unfortunately, we were forced to exclude the scan-

216 sampling data from our analysis due to circumstances beyond our control. Thus, we were unable

217 to measure relationship quality and its effect on levels of affiliative behavior in this study.

218 (f) Analysis

219 We used Wilcoxon signed-ranks tests (two-tailed) to analyze the differences between PD

220 and MC pairs because of the relatively small sample size. The data were analyzed by focal

221 individual to avoid biasing the data toward any particularly well-represented focal elephant. In

222 addition, the McNemar test was used to assess the presence or absence of elephant bunching

223 behavior within PD/MC observations (Siegel \& Castellan, 1988). All tests were two-tailed, and

224 P-values were compared to an alpha level of $\alpha=0.05$.

225 Results

226 (a) Physical affiliation following distress

227

To assess reassurance behavior, we first recorded the timing of the first affiliative

228

interaction between the victim (the first individual in a group to display distress behavior, i.e.

229 vocalizations and body state changes signaling emotional distress or agitation) and any

230 bystander(s), with physical contact and affiliative vocalizations analyzed separately. These data

231 were collected during the 10-min PD period and then compared to the timing of the first

232 affiliative interaction in the corresponding MC period. Following standard procedures developed

233 in primate studies (e.g., de Waal \& van Roosmalen, 1979; de Waal \& Yoshihara, 1983; de Waal \&

234 Aureli, 1996; Romero \& de Waal, 2010), PD/MC pairings were split into three categories:

235 attracted (pairings in which the first affiliative contact occurred earlier in the PD than in the MC,

236 or no contact occurred in the MC following contact in the PD), dispersed (contact occurred

237 earlier in the MC than in the PD or not at all in the PD), and neutral (affiliative contact times did 
not differ in the PD and its corresponding MC, or no contact occurred in either) (e.g., de Waal \& Yoshihara, 1983; Veenema, Das \& Aureli, 1994; Verbeek \& de Waal, 1997; Aureli \& de Waal, 2000).

There were $84 \mathrm{PD} / \mathrm{MC}$ observations (and thus 84 distinct initial instances of distress signals) across 18 different focal individuals (mean number of $\mathrm{PD} / \mathrm{MC}$ observations per individual $=9.5$, range $=1-38$ ). Within the $84 \mathrm{PD} / \mathrm{MC}$ observations, there were a total of 183 focal-bystander dyads, 171 of which involved at least one affiliative physical contact (e.g., Figure 1) during the PD period (93.4\%). 53 of the $84 \mathrm{PD} / \mathrm{MC}$ observations included affiliative contact by multiple individuals directed toward a single focal individual. 12 of the 84 observations were the result of an identifiable stimulus for distress - either directed aggression or a feature in the environment (e.g. helicopter, human or dog in close proximity) - that caused distress first in a single individual. The sample size did not allow for further analysis by stimulus type. In our analysis of affiliative contacts, we were concerned only with the first contacts between bystanders and the focal individual in each of the $84 \mathrm{PD} / \mathrm{MC}$ observations. The majority of affiliative contacts occurred within the first minute following distress (Figure 2; see Movie S1 for an example of affiliative contact), and a Wilcoxon signed-ranks test performed on the data by focal individual showed that the difference in frequency of these contacts per individual subject in the first minute of the $\mathrm{PD}($ mean $\pm \mathrm{SD}=7.50 \pm 8.49)$ versus the $\mathrm{MC}($ mean $\pm \mathrm{SD}=0.44 \pm$ 0.86) was significant $(\mathrm{Z}=3.56, \mathrm{n}=18, \mathrm{P}<0.001)$.

We categorized attracted and dispersed pairs based on whether or not each interaction was "solicited" (the focal, distressed individual approached a bystander to seek reassurance) or "unsolicited" (a bystander was the first to approach the focal, which is sometimes called "true consolation" in primate studies - Koski \& Sterck, 2007; Call, Aureli \& de Waal, 2002). When the first affiliative contacts between the focal individual and bystanders in each of the $84 \mathrm{PD} / \mathrm{MC}$ observations were analyzed (the usual first step in assessing consolation data - e.g., de Waal \& 
263 van Roosmalen, 1979; de Waal \& Yoshihara, 1983; de Waal \& Aureli, 1996; Romero \& de Waal,

264 2010), a significant difference was found between the proportion of attracted and dispersed pairs

265 in both unsolicited $(\mathrm{Z}=3.31, \mathrm{n}=18, \mathrm{P}<0.001)$ and solicited contacts $(\mathrm{Z}=2.69, \mathrm{n}=18, \mathrm{P}=$

266 0.007; Table 1). Across the 18 focal individuals, unsolicited contacts (mean $\pm \mathrm{SD}=8.83 \pm 11.93$ )

267 occurred significantly more often than solicited contacts (mean $\pm \mathrm{SD}=1.33 \pm 1.71 ; \mathrm{Z}=2.47, \mathrm{n}=$

$26818, \mathrm{P}=0.014)$. The two most prevalent types of physical contact given by bystanders were trunk

269 touches to another individual's genitals (38.6\% of touches), and trunk touches around or inside

270 another's mouth (35.1\%; Figure 3).

271 (b) Vocal affiliation following distress

272 Because elephants primarily use acoustic modalities for communication (e.g. Poole, 1996;

273 Payne, 2003; Nair et al., 2009; de Silva, 2010), we also looked at bystanders' vocalizations in

274 response to distressed individuals. In a comparison of first bystander vocalizations in the PD and

275 MC periods, we found that bystanders vocalized earlier following distress than in control periods

276 in a significant number of $\mathrm{PD} / \mathrm{MC}$ observations (proportion of attracted pairs: mean $\pm \mathrm{SD}=$

$27797.11 \% \pm 8.81 \%$; dispersed pairs: $2.22 \% \pm 8.61 \%$ ) across 18 focal individuals (incidentally, only

278 three of these focal individuals never had a bystander vocalize when they were distressed: $\mathrm{Z}=$

$2793.42, \mathrm{~N}=18, \mathrm{P}<0.001$ ). Bystander elephants most often chirped (a vocalization often emitted

280 when individuals are in close-proximity to one another $-31.8 \%$ of vocalizations) or audibly

281 trunk-bounced (interpreted as a sign of agitation or distress $-24.7 \%$ of vocalizations) following

282 distress signals from the focal animal (Olson, 2004; Nair et al., 2009; de Silva, 2010, see Figure

283 3).

284 In addition, we assessed differences in the behavior of bystanders in relation to the

285 behavior of distressed individuals between PD and MC periods. Vocalizations may signal

286 agitation or excitement in elephants and are usually paired with similarly functioning physical 
and postural displays (Olson, 2004; Nair et al., 2009; de Silva, 2010). Bystanders adopted the

288 agitated behavior of the originally distressed focal individual in the PD (e,g,, ears presented

289 forward with an erect tail, usually followed by several vocalizations and sometimes with

290 simultaneous urination and defecation - Olson, 2004; Bates et al., 2008), yet showed no such

291 signs of agitation or distress in the MC in 157 of the 171 dyads in which physical contact

292 occurred $(91.8 \%$ : mean $\pm \mathrm{SD}=8.72 \pm 9.51$ dyads per focal individual; $\mathrm{Z}=3.56, \mathrm{n}=18, \mathrm{P}<$

293 0.001).

\section{4 (c) Behavior among bystanders}

295 The previous results refer to contact by bystanders to a distressed, focal individual, but we

296 also analyzed contact between bystanders in PDs in which there were multiple individuals

297 present. Bystander-bystander physical contact occurred in 37 of the 84 PD periods, and, like in

298 victim-bystander contacts, occurred earlier following the victim's distress in the PD period than

299 in the MC in a significant number of interactions across 19 possible bystanders (proportion of

300 attracted pairs: mean $\pm \mathrm{SD}=97.37 \% \pm 8.36 \%$; dispersed pairs: $2.63 \% \pm 8.36 \% ; \mathrm{Z}=3.85, \mathrm{n}=19$,

$301 \mathrm{P}<0.001)$.

302 Elephants may quickly form a close circle, known as "bunching," around their young in

303 anti-predator defense (e.g., Moss, 1988; Poole, 1996; McComb et al., 2001; Bates et al., 2008).

304 Bunching involves the coming together of multiple individuals around the distressed elephant so

305 that all individuals are within trunk's reach of one another (Nair et al., 2009). To systematically

306 assess whether individual signs of distress trigger such behavior, we looked at the

307 occurrence/non-occurrence of bunching in PD/MC observations. We excluded all observations in

308 which less than four individuals were present (this excluded $n=7$ focal individuals altogether). In

30930 of the 42 qualifying PD/MC observations, bunching around both juveniles and other adults

310 occurred following distress and never in the corresponding control periods (McNemar change test 
311 comparing presence or absence of bunching in PD and control periods: $\chi^{2}=28.03, \mathrm{df}=1, \mathrm{P}<$ $3120.001)$.

\section{Discussion}

314 In this study, we set out to investigate the affiliative responses of elephants to others and

315 found that they engage in more such responses following distress than during control periods.

316 The elephants engaged significantly more often in unsolicited physical contacts (bystanders

317 approached and affiliated with the first-distressed individual) than in solicited contacts (the first-

318 distressed individual is the initiator of the contact). Bystanders also vocalized toward or in

319 response to distressed individuals, and made contact with each other significantly more often than

320 in controls.

321 In the study of consolation in animals, the stimulus event is almost always a conflict, and

322 the roles of the individual participants - victim, aggressor, bystander - are clearly differentiated.

323 In the present study, in contrast, the labels of "victim" and "bystander" were applied by labeling

324 the first individual to show distress following a known or unknown stimulus as the "victim",

325 while all nearby individuals were labeled "bystanders." In our study, temporal differences

326 between displays of distress were rather clear within these managed groups, with the bystanders

327 responding after the victim's first display of distress. This makes it unlikely that these responses

328 concerned the same stimulus, and suggests that they rather concerned the other's distress. If so,

329 the observed behavior is to be interpreted in the same way as consolation in primates, including

330 chimpanzees (Romero, Castellanos \& de Waal, 2010; Romero \& de Waal, 2010). Since our study

331 shows that, across distressed individuals, bystanders initiated affiliative contact more often than

332 did victims, the observed reactions seem similar to what is sometimes called "true consolation" in

333 nonhuman primates (de Waal \& Aureli, 1996; Romero, Castellanos \& de Waal, 2010; Romero \&

334 de Waal, 2010). 

contagion (Hatfield, Cacioppo \& Rapson, 1994; de Waal, 2003) may imply that the behavior has empathic underpinnings (Preston \& de Waal, 2002). In our study, the emotional response of multiple individuals to mostly unknown stimuli could be either contagious (multiple individuals adopt the emotional state of one) or universal (all individuals react with similar emotion to the same stimulus). Substantial anecdotal evidence of emotional contagion in elephants (e.g., Douglas-Hamilton \& Douglas-Hamilton, 1975; Moss, 1988; Poole, 1996; Schulte, 2000; Payne, 2003; Bates et al., 2008) suggests the presence of the required capacity, and the aforementioned temporal differences between the responses of victims and bystanders suggests emotional contagion in this study as well. However, we acknowledge that both interpretations are possible. This is the first systematic assessment of post-distress affiliative behavior in elephants, and this captive population provided sufficient opportunities to observe this species' capacity for reassurance. We recognize that wild elephant studies often delineate "family" subgroups from "non-family" subgroups through descriptions of affiliative behavior, and so we avoided this terminology since the origin of our subgroups is different. Instead, we focus solely on assessing the capacity for reassurance behavior and analyze how it is exhibited between individuals. The

351 confounds of elephant captivity did preclude us, however, from assessing how this behavior 352 varies with the quality of the relationship between individuals. The use of captive elephants however provides an opportunity to investigate whether or not elephants have the capacity for the same level of affiliative behavior following distress seen in consolatory species like the great apes. Future studies on wild elephants should confirm these results and those presented in anecdotal reports (e.g., Douglas-Hamilton et al., 2006; Bates et al., 2008; Hart, Hart \& PinterWollman, 2008), even though limitations exist on wild Asian elephant social observations (e.g.,

358 dense forest cover and the rarity of consistent, large family group sightings - Lair, 1997;

359 Sukumar, 2006; de Silva, Ranjeewa \& Kryazhimskiy, 2011). After all, the original studies of 
360

361

362

363

364

365

366

367

368

369

370

371

372

373

374

375

376

377

378

379

380

381

382

383

consolation in non-human primates were conducted on captive animals (e.g., de Waal \& van

Roosmalen, 1979; de Waal \& Aureli, 1996) and were confirmed only much later in the wild (e.g.,

Wittig \& Boesch 2003; Kutsukake \& Castles 2004).

This study of post-distress behavior is unique in that it goes beyond the traditional

attention to physical contact. The consistent use of vocalizations by bystanders to distressed companions may serve to reassure them, perhaps independent of or to complement physical touches. Both the overwhelming number of unsolicited contacts, and the prevalence of specific vocalizations (e.g. chirping, which may serve as a reassurance vocalization used when elephants are in close proximity to each other - Nair et al., 2009; de Silva, 2010) lend support to the notion that elephants use multiple communicative modalities (tactile and acoustic) in their affiliative interactions with others (e.g., Langbauer, 2000; McComb et al., 2000; Douglas-Hamilton et al., 2006; Bates et al., 2008). In addition, a bystander often affiliated physically with a distressed individual by touching or putting its trunk inside the victim's mouth. This may mirror similar vulnerable contact behavior seen in chimpanzees, whereby individuals put a finger or a hand into the mouth of a distressed other (de Waal, 1982; de Waal, 1990; Nishida et al., 2010).

Bystander affiliation directed toward others in distress, either in the form of consolation following conflict or reassurance following another stressful event, is rare in the animal kingdom possibly due to the unique cognitive mechanisms that may underlie it. Similarities in the complexity of chimpanzee and elephant social relationships (de Waal, 1982; Payne, 2003; Plotnik et al., 2006; Bates et al., 2008; de Waal, 2008; Byrne, Bates \& Moss, 2009; de Waal, 2009; de Silva, Ranjeewa, Kryazhimskiy, 2011; Moss, Croze \& Lee, 2011; Plotnik et al., 2011) suggest convergent cognitive evolution that should be further explored through careful analysis of social networks (de Silva, Ranjeewa \& Kryazhimskiy, 2011) and these species' use of multi-modal communication in negotiating their physical and social environments. 


\section{Acknowledgements}

385 We thank P. Panyawattanaporn and A. Vijit of the National Research Council of Thailand for their support. We thank T. Romero, P. Lee, L. Rogers and an anonymous reviewer for comments on an earlier version of this manuscript. We also thank S. Chailert for allowing us to study the Elephant

388 Nature Park's elephants, and J. Smith for his support in organizing the project. We are grateful to K. Cullen, G. Hayworth, G. Highet, J. Hilton, M. Kobylka, J. Schurer, and J. Thomas for field support, and the more than forty mahouts - elephant caretakers - who were a constant source of protection and encouragement. This paper is dedicated to the memory of Karl Cullen, one of the world's greatest elephant caretakers, without whom this study could not have been completed.

\section{References}

Altmann J (1974) Observational study of behaviour: Sampling methods. Behaviour 49: 227-267.

Aureli F, de Waal FBM, editors (2000) Natural conflict resolution. Berkeley: University of California Press.

Aureli F, van Schaik CP, van Hooff JARAM (1989) Functional aspects of reconciliation among captive long-tailed macaques (Macaca fascicularis). Am J Primatol 19: 39-51.

399 Bates LA, Lee PC, Njiraini N, Poole JH, Sayialel K, et al. (2008) Do elephants show empathy? J 400 Conscious Stud 15: 204-225.

401 Byrne RW, Bates LA, Moss CJ (2009) Elephant cognition in primate perspective. Comp Cog 402 Behav Rev 4: 1-15.

403 Call J, Aureli F, de Waal FBM (2002) Postconflict third-party affiliation in stumptailed macaques. 404 Anim Behav 63: 209-216.

405 Clay Z, de Waal FBM (2013) Development of socio-emotional competence in bonobos. Proc Natl 406 Acad Sci USA 110: 18121-18126.

407 Cools AKA, van Hout AJM, Nelissen MHJ (2008) Canine reconciliation and third-party-initiated 408 postconflict affiliation: do peacemaking social mechanisms in dogs rival those of higher 409 primates? Ethology 114: 53-63.

410 Cordoni G, Palagi E, Borgognini Tarli S (2006) Reconciliation and consolation in captive 411 Western gorillas. Intl J Primatol 27: 1365-1382.

412 de Silva S (2010) Acoustic communication in the Asian elephant, Elephas maximus maximus. 413 Behaviour 147: 825-852. 
414 de Silva S, Ranjeewa ADG, Kryazhimskiy S (2011) The dynamics of social networks among

415 female Asian elephants. BMC Ecology 11: 17.

416 de Waal FBM (1982) Chimpanzee politics. New York: Harper and Row.

417 de Waal FBM (1990) Peacemaking among primates. Cambridge, MA: Harvard University Press.

418 de Waal FBM (2000) Primates - a natural heritage of conflict resolution. Science 289: 586-590.

419 de Waal FBM (2003) On the possibility of animal empathy. In: Manstead T, Frijda N, Fischer A, 420 editors. Feelings and emotions: the Amsterdam symposium. Cambridge, UK: Cambridge 421 University Press. pp. 379-399.

422 de Waal FBM (2008) Putting the altruism back into altruism: The evolution of empathy. Annu 423 Rev Psychol 59: 279-300.

424 de Waal FBM (2009) The age of empathy: nature's lessons for a kinder society. New York:

425 Harmony Books.

426 de Waal FBM, Aureli F (1996) Consolation, reconciliation, and a possible cognitive difference 427 between macaques and chimpanzees. In: Russon AE, Bard KA, Parker ST, editors. Reaching into 428 thought: the minds of the Great Apes. Cambridge, UK: Cambridge University Press. pp. 80-110.

429 de Waal FBM, van Roosmalen A (1979) Reconciliation and consolation among chimpanzees. 430 Behav Ecol Sociobiol 5: 55-66.

431 de Waal FBM, Yoshihara D (1983) Reconciliation and redirected affection in rhesus monkeys. 432 Behaviour 85: 224-241.

433 Douglas-Hamilton I, Bhalla S, Wittemeyer G, Vollrath F (2006) Behavioural reactions of 434 elephants towards a dying and deceased matriarch. Appl Anim Behav Sci 100: 87-102.

435 Douglas-Hamilton I, Douglas-Hamilton O (1975) Among the elephants. New York: Viking Press.

436 Fraser ON, Bugnyar T (2010) Do ravens show consolation? Responses to distressed others. PLoS 437 ONE 5: e10605.

438 Fraser ON, Stahl D, Aureli F (2008) Stress reduction through consolation in chimpanzees. Proc 439 Natl Acad Sci USA 105: 8557-8562.

440 Hart BL, Hart LA, Pinter-Wollman N (2008) Large brains and cognition: Where do elephants fit 441 in? Neurosci Biobehav Rev 32: 86-98.

442 Hatfield E, Cacioppo JT, Rapson RL (1994) Emotional contagion. Cambridge, UK: Cambridge 443 University Press.

444 Koole SL (2009) The psychology of emotion regulation: An integrative review. Cognition and 445 Emotion 23: 4-41. 
446 Koski SE, Sterck EHM (2007) Triadic postconflict affiliation in captive chimpanzees: Does consolation console? Anim Behav 73: 133-142.

448 Koski SE, Sterck EHM (2009) Post-conflict third-party affiliation in chimpanzees: What's in it 449 for the third party? Am J Primatol 71: 409-418.

450 Kutsukake N, Castles DL (2004) Reconciliation and post-conflict third-party affiliation among 451 wild chimpanzees in the Mahale Mountains, Tanzania. Primates 45: 157-165.

452 Lair RC (1997) Gone astray: the care and management of the Asian elephant in domesticity. 453 Rome: Food Agric Org United Nations.

454 Langbauer Jr WR (2000) Elephant communication. Zoo Biol 19: 425-445.

455 Lee PC (1987) Allomothering among African elephants. Anim Behav 35: 278-291.

456 Mallavarapu S, Stoinski TS, Bloomsmith MA, Maple TL (2006) Postconflict behavior in captive 457 western lowland gorillas (Gorilla gorilla gorilla). Am J Primatol 68: 789-801.

458 McComb K, Moss C, Sayialel S, Baker L (2000) Unusually extensive networks of vocal 459 recognition in African elephants. Anim Behav 59: 1103-1109.

460 McComb K, Moss C, Durant SM, Baker L, Sayialel S (2001) Matriarchs as repositories of social 461 knowledge in African elephants. Science 292: 491-494.

462 Moss C (1988) Elephant memories: thirteen years in the life of an elephant family. New York:

463 Fawcett Columbine.

464 Moss CJ, Croze HJ, Lee PC, editors (2011) The Amboseli elephants: a long-term perspective on a 465 long-lived mammal. Chicago: University of Chicago Press.

466 Nair S, Balakrishnan R, Seelamantula CS, Sukumar R (2009) Vocalizations of wild Asian 467 elephants (Elephas maximus): Structural classification and social context. J Acoust Soc Am 126: $468 \quad 2768-2778$.

469 Nishida T, Zamma K, Matsusaka T, Inaba A, McGrew WC (2010) Chimpanzee behaviour in the 470 wild: an audio-visual Encyclopedia. Tokyo: Springer.

471 Olson D, editor (2004) Elephant husbandry resource guide. Lawrence, KS: Allen Press.

472 Palagi E, Cordoni G (2009) Postconflict third-party affiliation in Canis lupus: Do wolves share 473 similarities with the great apes? Anim Behav 78: 979-986.

474 Palagi E, Cordoni G, Tarli SB (2006) Possible roles of consolation in captive chimpanzees (Pan 475 troglodytes). Am J Phys Anthropol 129: 105-111.

476 Palagi E, Paoli T, Tarli SB (2004) Reconciliation and consolation in captive Bonobos (Pan 477 paniscus). Am J Primatol 62: 15-30. 
478 Payne K (2003) Sources of social complexity in the three elephant species. In: de Waal FBM, 479 Tyack PL, editors. Animal social complexity: intelligence, culture, and individualized societies.

480 Cambridge, MA: Harvard University Press. pp. 57-85.

481 Plotnik JM, de Waal FBM, Reiss D (2006) Self-recognition in an Asian elephant. Proc Natl Acad 482 Sci USA 103: 17053-17057.

483 Plotnik JM, Lair R, Suphachoksahakun W, de Waal FBM (2011) Elephants know when they need 484 a helping trunk in a cooperative task. Proc Natl Acad Sci USA 108: 5116-5121.

485 Poole J (1996) Coming of age with elephants. New York: Hyperion.

486 Preston SD, de Waal FBM (2002) Empathy: Its ultimate and proximate bases. Behav Brain Sci $487 \quad 25: 7-71$.

Romero T, Castellanos MA, de Waal FBM (2010) Consolation as possible expression of sympathetic concern among chimpanzees. Proc Natl Acad Sci USA 107: 12110-12115.

Romero T, Castellanos MA, de Waal FBM (2011) Post-conflict affiliation by chimpanzees with aggressors: Other-oriented versus selfish political strategy. PLoS ONE 6: e22173.

492 Romero T, de Waal FBM (2010) Chimpanzee (Pan troglodytes) consolation: Third-party identity 493 as a window on possible function. J Comp Psychol 124: 278-286. Psychol 188: 340-346.

497 Schulte BA (2000) Social structure and helping behavior in captive elephants. Zoo Biol 19: 447498459.

499 Seed AM, Clayton NS, Emery NJ (2007) Postconflict third-party affiliation in rooks, Corvus 500 frugilegus. Curr Biol 17: 152-158.

501 Siegel S, Castellan Jr NJ (1988) Nonparametric statistics for the behavioral sciences. New York: 502 McGraw-Hill.

503 Sukumar R (2003) The living elephants: evolutionary ecology, behavior, and conservation. 504 Oxford, UK: Oxford University Press.

505 Sukumar R (2006) A brief review of the status, distribution and biology of wild Asian elephants, 506 Elephas maximus. Intl Zoo Yrbk 40: 1-8.

507 Veenema HC, Das M, Aureli F (1994) Methodological improvements for the study of 508 reconciliation. Behav Processes 31: 29-37.

509 Verbeek P, de Waal FBM (1997) Postconflict behaviour of captive brown capuchins in the 510 presence and absence of attractive food. Intl J Primatol 18: 703-725. 
511 Watts DP, Colmenares F, Arnold K (2000) Redirection, consolation and male policing: How

512 targets of aggression interact with bystanders. In: Aureli F, de Waal FBM, editors. Natural

513 conflict resolution. Berkeley: University of California Press. pp. 281-301.

514 Wittig RM, Boesch C (2003) The choice of post-conflict interactions in wild chimpanzees (Pan

515 troglodytes). Behaviour 140: 1527-1559.

516 Wittig RM, Crockford C, Wikberg E, Seyfarth RM, Cheney DL (2007) Kin-mediated

517 reconciliation substitutes for direction reconciliation in female baboons. Proc Royal Soc B 274:

518 1009-1115.

519 Zahn-Waxler C, Hollenbeck B, Radke-Yarrow M (1984) The origins of empathy and altruism. In:

520 Fox MW, Mickley D, editors. Advances in animal welfare science. Washington: Humane Society. 521 pp. 21-39.

522 Zahn-Waxler C, Radke-Yarrow M (1990) The origins of empathic concern. Motiv Emot 14: 107523130.

524 Zahn-Waxler C, Radke-Yarrow M, Wagner E, Chapman M (1992) Development of concern for 525 others. Dev Psychol 28: 126-136. 


\section{Table 1 (on next page)}

Solicited and unsolicited affiliative contacts for each focal individual across all 183 focalbystander dyads, within $84 \mathrm{PD} / \mathrm{MC}$ observations.

Columns indicate numbers of attracted (A), dispersed (D) and neutral $(N)$ pairs per individual in both solicited (S) and unsolicited (US) contacts. Totals are provided in italics. The Mean \pm $\mathrm{SD}$ indicates the mean proportion of attracted and dispersed pairs \pm the standard deviation. 


\begin{tabular}{lcccccc} 
Focal & A $(\mathbf{S})$ & $\mathbf{D}(\mathbf{S})$ & $\mathbf{N}(\mathbf{S})$ & $\mathbf{A}(\mathbf{U S})$ & $\mathbf{D}(\mathbf{U S})$ & $\mathbf{N}(\mathbf{U S})$ \\
\hline AU & 3 & 0 & 0 & 11 & 1 & 1 \\
BT & 3 & 0 & 0 & 7 & 0 & 1 \\
F & 2 & 0 & 0 & 12 & 0 & 1 \\
JB & 0 & 0 & 0 & 2 & 0 & 0 \\
JK & 0 & 0 & 0 & 26 & 0 & 2 \\
MB & 2 & 0 & 0 & 11 & 0 & 0 \\
MD & 0 & 0 & 0 & 3 & 0 & 0 \\
MEL & 3 & 0 & 0 & 0 & 0 & 0 \\
MK & 0 & 0 & 0 & 2 & 0 & 0 \\
ML & 1 & 0 & 0 & 0 & 0 & 1 \\
MLT & 0 & 0 & 0 & 2 & 0 & 0 \\
MP & 6 & 0 & 0 & 1 & 0 & 0 \\
MTK & 3 & 0 & 0 & 0 & 0 & 0 \\
MVL & 0 & 0 & 0 & 3 & 1 & 0 \\
SB & 0 & 0 & 0 & 0 & 0 & 1 \\
TD & 0 & 0 & 0 & 2 & 0 & 0 \\
TJ & 1 & 0 & 0 & 33 & 1 & 9 \\
TT & 0 & 0 & 0 & 19 & 4 & 2 \\
Group & 24 & 0 & 0 & 134 & 7 & 18 \\
\hline Mean \pm & $100 \% \pm$ & & & $80.31 \%$ & $3.19 \% \pm$ & \\
SD & 0 & & & \pm 32.71 & 7.23 & \\
\hline
\end{tabular}

Table 1. Solicited and unsolicited affiliative contacts for each focal individual across all 183 focal-bystander dyads, within 84 PD/MC observations. Columns indicate numbers of attracted (A), dispersed (D) and neutral (N) pairs per individual in both solicited (S) and unsolicited (US) contacts. Totals are provided in italics. The Mean \pm SD indicates the mean proportion of attracted and dispersed pairs \pm the standard deviation. 


\section{Figure 1}

Physical contact between elephants following distress included trunk touches to the genitals, mouth and the rest of the head (as seen here).

Photograph taken by E. Gilchrist at the Golden Triangle Asian Elephant Foundation, Chiang Rai, Thailand.

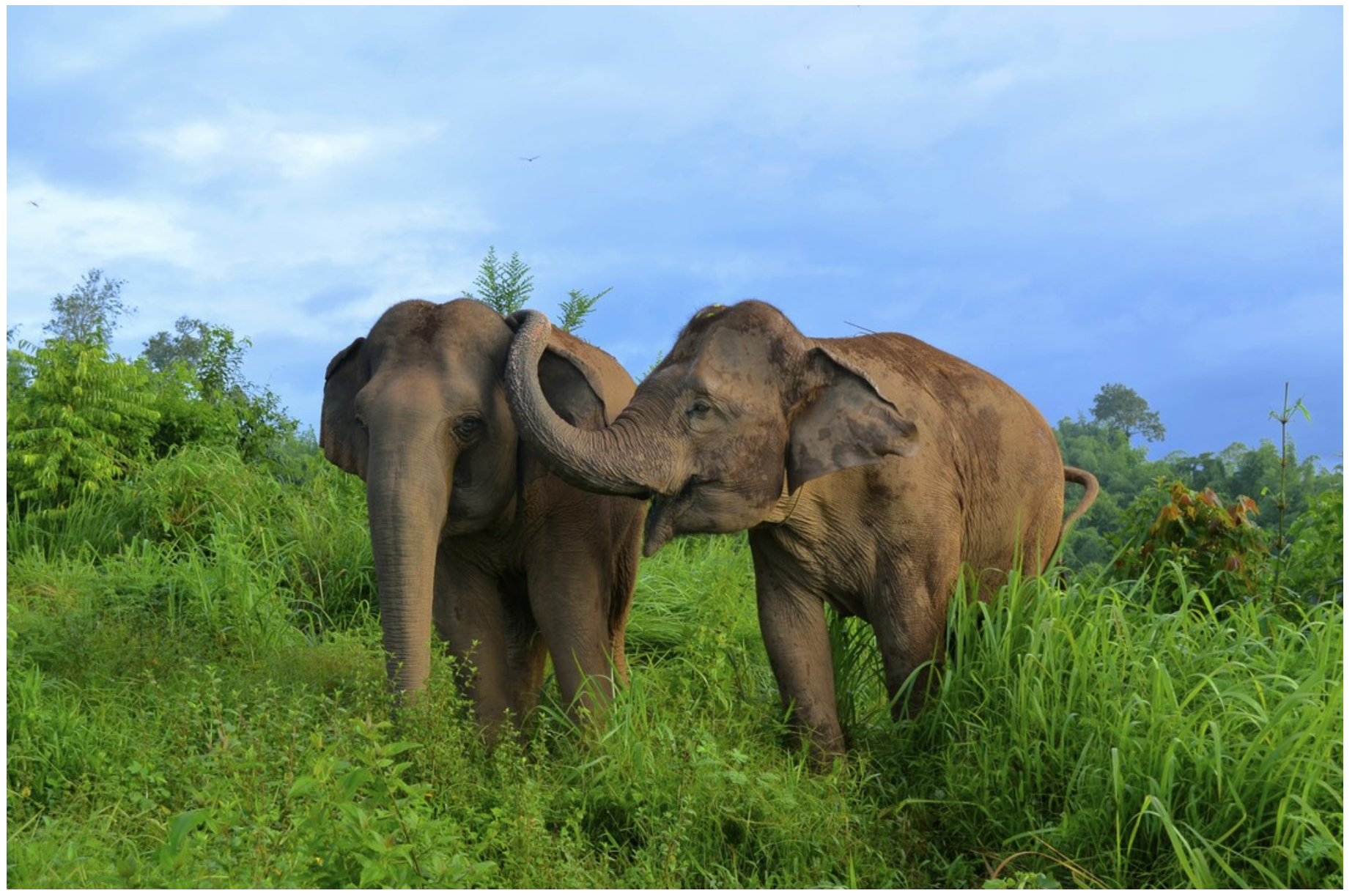




\section{Figure 2}

Temporal distribution of the first affiliative, physical contacts in PD (closed diamonds) and MC (open squares) periods across all dyads.

The number of first contacts occurred overwhelmingly in the first minute following the distress signal, which is consistent with consolation studies in other species (Aureli, van Schaik \& van Hooff, 1989). See Movie S1 for an example of physical and vocal contact.

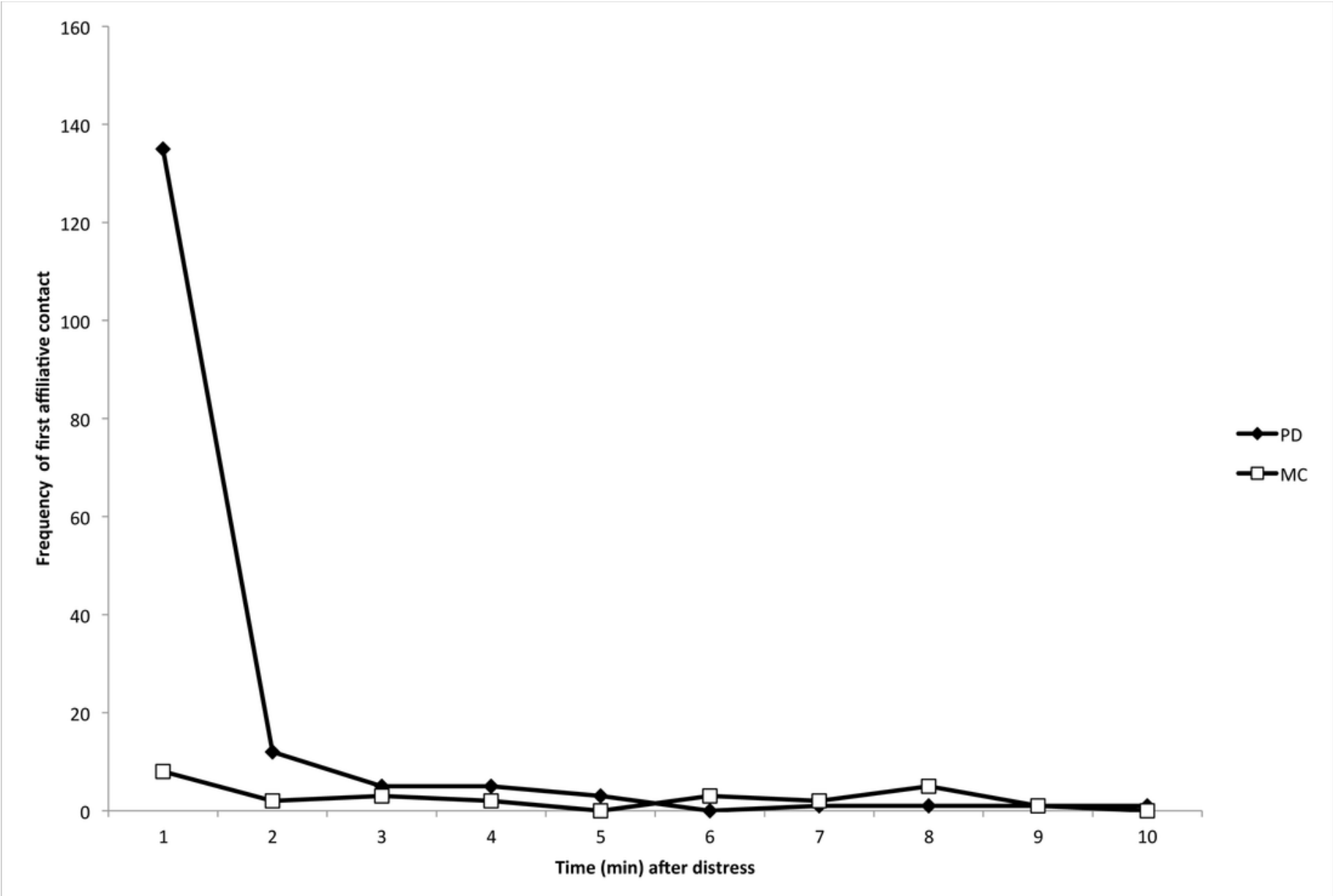




\section{Figure 3}

Frequency of each type of first contact or bystander response.

Vocalisations: VC - chirp, TS - trunk smack or trunk bounce, VT - trumpet, VS - roar, VR rumble. Touches: TG - genitals, TM - mouth, TF - rest of face / head, TB - rest of body, TT - trunk/trunk, BF - breast-feeding. The y-axis indicates the percent (\%) occurrence of each type of vocalisation or trunk touch as the first affiliative contact or response across all dyads.

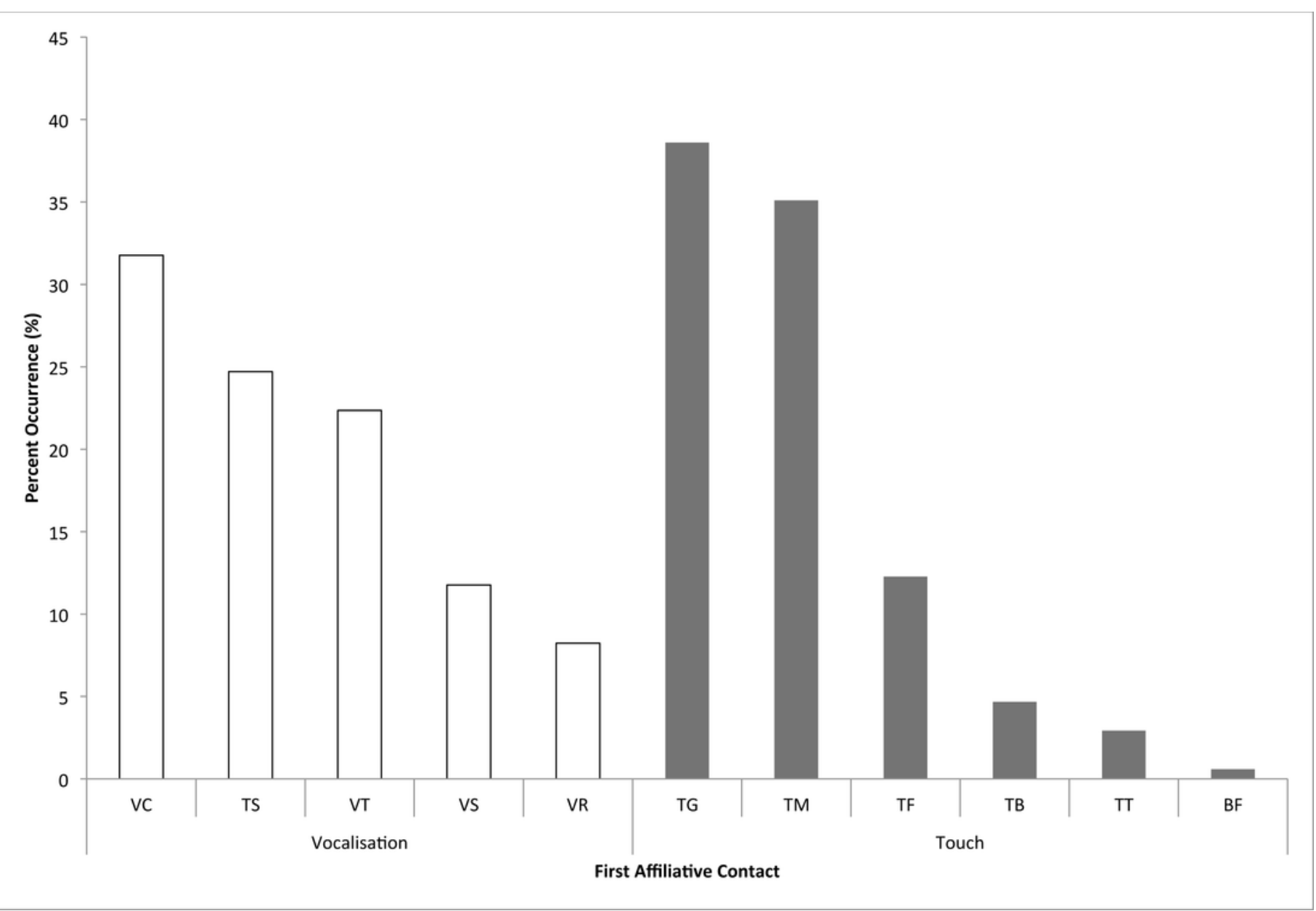

